\title{
Effects of xylazine on acid-base balance and arterial blood-gas tensions in goats under different environmental temperature and humidity conditions
}

\author{
E G M Mogoa ${ }^{a^{*}}$, G F Stegmann ${ }^{a}$ and A J Guthrie ${ }^{b}$
}

\begin{abstract}
Theeffects of acuteexposureto 3 different temperatureand humidity conditionson arterial blood-gas and acid-base balance in goats were investigated after intravenous bolus administration of xylazine at a dose of $0.1 \mathrm{mg} / \mathrm{kg}$. Significant $(P<0.05)$ changes in the variables occurred under all 3environmental conditions. Decreasesin $\mathrm{pH}$, partial pressure of oxygen and oxyhaemoglobin saturation were observed, and the minimum values for oxygen tension and oxyhaemoglobin saturation were observed within $5 \mathrm{~min}$ of xylazine administration. The $\mathrm{pH}$ decreased to its minimum values between 5 and $15 \mathrm{~min}$. Thereafter, the variables started to return towards baseline, but did not reach baseline values at the end of the 60 min observation period. Increases in the partial pressure of carbon dioxide, total carbon dioxide content, bicarbonate ion concentration, and the actual base excess were observed. The maximum increase in the carbon dioxide tension occurred within 5 min of xylazineadministration. Theincrease in theactual base excess only becamesignificant after $30 \mathrm{~min}$ in all 3 environments, and maximal increases were observed at $60 \mathrm{~min}$. There were no significant differences between the variables in the 3 different environments. It was concluded that intravenous xylazineadministration in goats resulted in significant changes in arterial blood-gas and acid-base balance that were associated with hypoxaemia and respiratory acidosis, followed by metabolic alkalosis that continued for the duration of the observation period. Acute exposure to different environmental temperatureand humidity conditions after xylazine administration did not influencethechanges in arterial blood-gas and acid-base balance.
\end{abstract}

Key words: acid-base, anaesthesia, blood-gas, goats, xylazine.

Mogoa E G M, Stegmann G F, Guthrie A J. Effects of xylazine on acid-base balance and arterial blood-gas tensions in goats under different environmental temperature and humidity conditions. Journal of the South A frican Veterinary A ssociation (2000) 71(4): 229-231 (En.). Department of Companion Animal Surgery, Faculty of Veterinary Science, University of Pretoria, Private Bag X04, Onderstepoort, 0110 South Africa.

\section{INTRODUCTION}

Xylazine is widely used in various animal species for its potent sedative, analgesic and myorelaxant properties ${ }^{5}$. Reported adverse effects of xylazine are hypoxaemia, carbon dioxide retention and acid-base disturbances ${ }^{4-7,10,11,16,17,21}$. The field use of xylazine often requires the administration of this agent to compromised animals exposed to acute changes in environmental conditions. Xylazine administered to heat-stressed heifers resulted in a prolonged action of xylazine . $^{8}$ It was speculated that the duration of the effect of xylazine might be altered during acute changes in environmental conditions, and therefore result in increased morbidity or mortality. The purpose of

\footnotetext{
a Department of Companion Animal Surgery, Faculty of Veterinary Science, University of Pretoria, Private Bag X04, Onderstepoort, 0110 South Africa.

${ }^{b}$ Equine Research Centre, Faculty of Veterinary Science, University of Pretoria.

*Present address: Department of Clinical Studies, Faculty of Veterinary Medicine, University of Nairobi, PO Box 29053, Nairobi, Kenya.

Received: November 1999. Accepted: August 2000.
}

this study was therefore to evaluate the short term effects of xylazine in goats under different environmental temperature and humidity conditions.

\section{MATERIALS AND METHODS}

Six adult, dinically healthy, non-descript indigenous African breed, castrated male goats, weighing between 21.0 and $34.0 \mathrm{~kg}$ (mean $28.2 \pm 1.0$ SEM), were used in this study. They were housed indoors in individual crates in premises devoid of temperature and humidity control. At least 1 month before the commencement of the study, the carotid artery was relocated to a subcutaneous position in all theanimalsunder halothaneanaesthesia. The protocol for this study was approved by the Ethicsand Research Committees of the Faculty of Veterinary Science, University of Pretoria.

A single-group, 3-phase crossover design was used in this investigation. The effects of the drug on acid-base balance and arterial blood gastension wererepeatedly examined during low, medium and high temperature and humidity exposure phases. A washout period of at least 7 days was allowed between phases. The first phase was conducted in the medium temperature and humidity environment with room temperature set at $24 \pm 1^{\circ} \mathrm{C}$, and a relativehumidity of $55 \pm 1 \%$. Phase 2 of the study was conducted in the high temperature and humidity environment with room temperature set at $34 \pm 1^{\circ} \mathrm{C}$, and arelativehumidity of $65 \pm 1 \%$. Phase 3 of the study was conducted in the low temperature and humidity environment with the room temperature set at 14 $\pm 1{ }^{\circ} \mathrm{C}$, and a relative humidity of $33 \pm$ $1 \%$. Temperature and humidity control was set $12 \mathrm{~h}$ before each phase of the investigation to ensureuniformity of conditions in the room. Before the investigation, the goats were starved for $24 \mathrm{~h}$ and water was withheld for $12 \mathrm{~h}$. The goats were weighed, restrained in lateral recumbency and the jugular grooves bilaterally surgically prepared for percutaneous venipuncture of the left jugular vein with a $18 \mathrm{G}$ catheter $\left(\mathrm{Jelco}{ }^{\circledR}\right.$, Critikon) for drug administration. The relocated carotid artery on the right side was catheterised with a $20 \mathrm{G}$ catheter (Medican ${ }^{\circledR}$, Medical Specialities) for arterial blood collection. Both catheters were flushed with heparinised saline, capped and sutured to theskin with No. 2/0nylon (Ethicon). The animals were then transferred to the temperature- and humiditycontrolled room, and maintained in lateral recumbency. An oesophageal thermometer probe from a multi-parameter physiological monitor (Propaq ${ }^{\circledR}$ 104EL, Protocol Systems, Oregon) was nasally introduced with the tip in the distal third of the oesophagus. After a stabilisation period of $10 \mathrm{~min}$, xylazine hydrochloride (Rompun ${ }^{\circledR}$, Bayer Animal Health, Isando) was injected intravenously as a bolus at a dose of $0.1 \mathrm{mg} / \mathrm{kg}$ body mass. Arterial blood samples ( $2 \mathrm{~m}$ ) were anaerobically collected from the carotid artery into $2.5 \mathrm{me}$ heparinised syringes and stored in iced water for analysis within $2 \mathrm{~h}$ of collection with a blood-gas analyser (Radiometer ABL 300, Copenhagen, Denmark). The samples were corrected for 
Table 1: Mean ( \pm SEM) of arterial blood-gas tensions and acid-base balance in goats following intravenous xylazine at a dose of $0.1 \mathrm{mg} / \mathrm{kg}$, under 3 different environmental temperature and humidity conditions.

\begin{tabular}{|c|c|c|c|c|c|c|c|c|}
\hline Time (min) & Environment & $\mathrm{pH}^{\mathrm{a}}$ & $\mathrm{PaO}_{2}^{\mathrm{b}}$ & $\mathrm{PaCO}_{2}^{\mathrm{C}}$ & $\mathrm{O}_{2} \mathrm{SAT}^{\mathrm{d}}$ & {$\left[\mathrm{HCO}_{3}^{-}\right]^{\mathrm{e}}$} & Total $\mathrm{CO}_{2}{ }^{\dagger}$ & $\mathbf{A B E}^{g}$ \\
\hline 0 & $14^{\circ} \mathrm{C}$ & $7.39(0.01)$ & $10.7(0.6)$ & $4.9(0.2)$ & $93.2(1.0)$ & $21.3(0.7)$ & $22.3(0.8)$ & $-2.2(0.7)$ \\
\hline 5 & & $7.34(0.01)^{*}$ & $4.0(0.4)^{\star}$ & $5.9(0.3)^{*}$ & $43.5(6.3)^{*}$ & $22.4(0.8)$ & $23.6(0.8)^{*}$ & $-2.3(0.7)$ \\
\hline 15 & & $7.35(0.01)$ & $5.2(0.5)^{*}$ & $5.9(0.3)^{*}$ & $62.3(6.0)^{*}$ & $23.1(0.7)^{\star}$ & $24.4(0.7)^{*}$ & $-1.6(0.6)$ \\
\hline 30 & & $7.37(0.01)$ & $5.8(0.5)^{*}$ & $5.7(0.2)^{*}$ & $71.5(5.2)^{*}$ & $24.0(0.8)^{*}$ & $25.2(0.8)^{*}$ & $-0.5(0.7)$ \\
\hline 60 & & $7.43(0.01)$ & $6.9(0.5)^{*}$ & $5.2(0.2)$ & $84.2(2.5)$ & $25.2(1.0)^{*}$ & $26.3(1.0)^{*}$ & $1.4(0.9)^{*}$ \\
\hline 0 & $24^{\circ} \mathrm{C}$ & $7.39(0.01)$ & $10.5(0.5)$ & $4.9(0.1)$ & $92.9(2.5)$ & $20.7(0.6)$ & $21.7(0.6)$ & $-2.9(0.6)$ \\
\hline 5 & & $7.33(0.01)^{\star}$ & $4.0(0.4)^{\star}$ & $6.3(0.2)^{*}$ & $43.5(5.6)^{*}$ & $22.5(0.5)^{*}$ & $23.5(0.6)$ & $-2.6(0.5)$ \\
\hline 15 & & $7.33(0.01)^{\star}$ & $4.8(0.5)^{\star}$ & $6.2(0.2)^{*}$ & $56.1(6.4)^{\star}$ & $23.4(0.7)^{*}$ & $24.6(0.7)^{*}$ & $-1.8(0.6)$ \\
\hline 30 & & $7.38(0.01)$ & $5.7(0.4)^{*}$ & $5.8(0.3)^{*}$ & $71.0(4.0)^{*}$ & $24.5(0.8)^{*}$ & $25.7(0.9)^{*}$ & $0.1(0.5)^{*}$ \\
\hline 60 & & $7.41(0.01)$ & $8.2(0.8)^{*}$ & $5.5(0.1)$ & $86.5(3.3)$ & $25.3(1.1)^{*}$ & $26.5(1.1)^{*}$ & $1.5(1.0)^{*}$ \\
\hline 0 & $34^{\circ} \mathrm{C}$ & $7.40(0.01)$ & $10.0(0.2)$ & $5.0(0.1)$ & $92.6(0.8)$ & $22.0(0.3)$ & $23.0(0.3)$ & $-1.4(0.3)$ \\
\hline 5 & & $7.35(0.01)^{\star}$ & $4.0(0.6)^{\star}$ & $6.1(0.1)^{*}$ & $42.0(8.8)^{\star}$ & $24.1(0.5)^{*}$ & $25.3(0.5)^{*}$ & $-0.6(0.6)$ \\
\hline 15 & & $7.36(0.01)^{*}$ & $4.9(0.6)^{*}$ & $6.0(1.4)^{*}$ & $56.6(7.2)^{*}$ & $24.3(0.6)^{*}$ & $25.6(0.7)^{*}$ & $-0.3(0.7)$ \\
\hline 30 & & $7.39(0.01)$ & $5.6(0.5)^{*}$ & $5.9(0.1)^{*}$ & $68.4(5.0)^{*}$ & $25.7(0.7)^{*}$ & $26.9(0.7)^{\star}$ & $1.5(0.8)^{\star}$ \\
\hline 60 & & $7.41(0.01)$ & $8.3(1.0)^{*}$ & $5.2(0.1)$ & $85.5(3.2)$ & $25.0(0.8)$ & $26.1(0.8)^{*}$ & $1.8(0.8)^{\star}$ \\
\hline
\end{tabular}

${ }^{\mathrm{a}} \mathrm{pH}$ units.

${ }^{\mathrm{b}} \mathrm{PaO}_{2}=$ arterial partial pressure of oxygen $(\mathrm{kPa})$.

${ }^{\mathrm{C}} \mathrm{PaCO}_{2}=$ arterial partial pressure of carbon dioxide $(\mathrm{kPa})$.

${ }^{\mathrm{d}} \mathrm{O}_{2} \mathrm{SAT}=$ oxyhaemoglobin saturation (\%).

${ }^{\mathrm{e}}\left[\mathrm{HCO}_{3}\right]=$ bicarbonate ion concentration $(\mathrm{mmol} / \mathrm{l})$

${ }^{\mathrm{f}} \mathrm{Total} \mathrm{CO}_{2}=$ total carbon dioxide content $(\mathrm{mmol} / \mathrm{l})$.

${ }^{9} \mathrm{ABE}=$ actual base excess $(\mathrm{mmol} / \mathrm{l})$.

*Significantly different $(P<0.05)$ from baseline (time $0 \mathrm{~min}$ ).

body temperature. The samples were collected at 'time zero' (baseline) and 5, $15,30,45$, and $60 \mathrm{~min}$ post-xylazine injection. The blood was analysed for $\mathrm{pH}$, arterial partial pressures of oxygen $\left(\mathrm{PaO}_{2}\right)$ and carbon dioxide $\left(\mathrm{PaCO}_{2}\right)$, oxyhaemoglobin saturation (SAT), bicarbonate ion concentration $\left[\mathrm{HCO}_{3}^{-}\right]$, actual base excess (ABE) and total carbon dioxide content $\left(\mathrm{TCO}_{2}\right)$.

\section{Data analysis}

The data in these studies were analysed on a personal computer equipped with statistical software (SigmaStat 2.0, Jandel Corporation, San Rafael). Results are presented as mean and standard error of the mean ( \pm SEM). To test for significance of difference over time as well as for differences between groups, data collected over time were analysed using a 2-way repeated measures analysis of variance. When a significant change was observed, comparisons between treatments were performed using a 1-way analysis of variance for repeated measures, followed by Bonferroni's test applied to examine for least significant differences. To test for significant changes with time within a group, a 1-way analysis of variance for repeated measures was applied followed by Bonferroni's test if significant changes were found. Where the data were either not normally distributed or the equal variance test failed, the data were analysed using Friedman repeated measures analysis of variance on ranks followed by Dunnett's method to examine deviations from baseline or 'time zero' (control) values. $P<0.05$ was considered significant.

\section{RESULTS}

The results of the mean ( \pm SEM ) arterial blood-gas tensions and acid-base balance variables of the goats under the different environmental conditions are summarised in Table 1. Intravenous administration of xylazine resulted in a transient period of grunting, limb paddling, irregular breathing, and brief periods of apnoea. Cyanosis of the oral mucous membrane was observed in all animals. This was followed by a period of deep sedation. The effects on cardiopulmonary function and changes in body temperature have been reported in full $I^{14}$. Body temperature increased in the $34^{\circ} \mathrm{C}$ environment with a maximum of $0.5^{\circ} \mathrm{C}$, and decreased in the 14 and $24^{\circ} \mathrm{C}$ environments with a maximum decrease of $1.5^{\circ} \mathrm{C}$ in the $14^{\circ} \mathrm{C}$ environment $^{14}$

Xylazine caused statistically significant $(\mathrm{P}<0.05)$ changes in $\mathrm{pH}, \mathrm{PaO}_{2}, \mathrm{SAT}$, $\mathrm{PaCO}_{2}, \mathrm{TCO}_{2},\left[\mathrm{HCO}_{3}^{-}\right]$, and SBE within 5 min of administration, except for the $\left[\mathrm{HCO}_{3}{ }^{-}\right]$in the $14^{\circ} \mathrm{C}$ environment, $\mathrm{TCO}_{2}$, at the $24^{\circ} \mathrm{C}$ environment, and the $\mathrm{ABE}$ in all 3 environments. The maximum de crease in $\mathrm{PaO}_{2}$ and SAT occurred within $5 \mathrm{~min}$ of xylazine administration. The $\mathrm{PaO}_{2}$ decreased to $4.0(0.4) \mathrm{kPa}$ in the $14^{\circ} \mathrm{C}$ environment and the SAT to values between 42 (8.8) and 43.5 (6.3) \% under the 3 environmental temperatures. The $\mathrm{PaO}_{2}$ and the calculated acid-base variables, $\mathrm{SBE}$ and $\mathrm{TCO}_{2}$, remained significantly different from baseline in all 3 environments at the end of the $60 \mathrm{~min}$ observation period.

\section{DISCUSSION}

Acute changes in environmental temperature and humidity conditions did not effect arterial blood-gas and acidbase variables in xylazine-treated goats. However, significant $(P<0.05)$ changesin arterial blood-gas tensions and acid-base balance (Table 1) were observed under all 3 sets of environmental conditions. The administration of xylazine was also associated with deep sedation, and changes in cardiopulmonary function ${ }^{15}$ and body temperature ${ }^{14}$.

The changes in arterial blood-gas and acid-base balance variables observed in this investigation were in agreement with changes previously reported in cattle $^{2,6,20}$, goats ${ }^{10,11}$ and sheep ${ }^{3,4}$. The time of maximal change (after $5 \mathrm{~min}$ ) was somewhat shorter compared to the previously reported times of maximal change around $10-15 \mathrm{~min}$. This was probably the result of intravenous administration and the higher dose $(0.1 \mathrm{mg} / \mathrm{kg})$ used for xylazine in this investigation. The acute decreases in the $\mathrm{PaCO}_{2}, \mathrm{PaO}_{2}$, SAT and cyanosis were probably the result of the effects of xylazine on cardiopulmonary function ${ }^{15}$. Arterial hypoxaemia associated with minimum oxygen tensions of $4 \mathrm{kPa}$ under all 3 environmental conditions were in agreement with the reported oxygen tensions in sheep of 
$4.3 \mathrm{kPa}^{4}$. Hypoxaemia was also reported in other species ${ }^{5,7,8,13}$. The hypoxaemia observed in this investigation was independent of environmental conditions and probably partly the result of hypoventilation due to central respiratory depressant effects of the drug ${ }^{1,20}$. Changes in breathing such as bradypnoea, tachypnoea, forced breathing and apnoea as observed in this investigation have been reported previously ${ }^{4,9,21}$. A decrease in tidal volume has also been reported in goats $^{13}$. Restraint in lateral recumbency might also have contributed to the changes observed in this investigation. It has been reported in cattle that restraint contributes to similar changes as a result of ventilation-perfusion mismatch, although there is a large difference in body size compared to goats ${ }^{6}$. Changes in pulmonary function associated with changes in transpulmonary pressure as a result of partial upper respiratory tract obstruction were reported in sheep after xylazine administration. It has been suggested that these changes were the result of $\alpha_{2}$-adrenoceptor-mediated activity ${ }^{4,20}$. De creases in arterial oxygen tension, haemoglobin saturation, and packed cell volume in compromised animals with anaemia may have an unfavourable effect on peripheral oxygen delivery, especially if associated with decreases in cardiac output and arterial blood pressure ${ }^{6,19}$. This may result in increased morbidity or mortality in animals.

Arterial $\mathrm{pH}$ decreased below baseline within 5 min of xylazineadministration as result of an increased $\mathrm{PaCO}_{2}$ (respiratory acidosis). The $\mathrm{PaCO}_{2}$ started to improve towards baseline after $30 \mathrm{~min}$, probably as result of recovery from xylazine. However, both $\mathrm{PaCO}_{2}$ and the total $\mathrm{CO}_{2}$ remained above baseline. Increases in $\left[\mathrm{HCO}_{3}{ }^{-}\right]$above baseline occurred over the observation period, and resulted in metabolic alkalosis. The arterial $\mathrm{pH}$ was increased above baseline values at $60 \mathrm{~min}$ for all 3 sets of environmental conditions despite the $\mathrm{PaCO}_{2}$ and total $\mathrm{CO}_{2}$ that were above baseline. The metabolic al kal osis is in agreement with a previous report in goats, although the magnitude of the alkalosis washigher, with a $\mathrm{pH}$ of approximately 7.48 and a BE of $5 \mathrm{mmol} / \mathrm{l}$ after administration of intravenous medetomidine ${ }^{18}$. The $60 \mathrm{~min}$ observation period used in this investigation may not beoptimal for the detection of maximal changes in acid-base variables.
The changes in the acid-base balance and blood-gas tensions observed in this investigation were independent of changes in environmental temperature and humidity conditions. The prolonged action of xylazine in heifers in an environment conducive to heat stress was observed after prolonged exposure to increased ambient temperature. It has been suggested that long-term metabolic changes such as decreased thyroid function and metabolic rate may result in the altered dinical effects of xylazine ${ }^{8,12}$. In comparison, the goats in this investigation were exposed to acute changes in the environment, which would not permit metabolic or hormonal changes, and could explain the reason for not observing similar changes in the response to xylazine.

In conclusion, intravenous xylazine in goats exposed to acute changes in environmental temperature and humidity conditions resulted in hypoxaemia, respiratory acidosis, and compensatory metabolic alkalosis. The changes were statistically significant under all 3 sets of environmental conditions, but no significant differences were observed between the different environments.

\section{ACKNOWLEDGEMENTS}

We would like to thank the Kenya Government, the International Development Association, International Bank for Reconstruction and Development, the World Bank, Bayer - Animal Health Division, South Africa, and the University of Pretoria for their financial and material support.

\section{REFERENCES}

1. Aithal H P, Pratap K A, Singh G R 1996 Clinical effects of epidurally administered ketamine and xylazine in goats. Small Ruminant Research 24: 55-64

2. Aouad I J, Wright M E, Shaner W T 1981 Anaesthesia evaluation of ketamine and xylazine in calves. Bovine Practice 2: 22-31

3. Aziz M A, Carlyle S S 1978 Cardiovascular and respiratory effects of xylazine in sheep. Zentralblatt für Veterinärmedizin (A)25: 173-180

4. Celly C S, McDonell W N, Young SS, Black W D 1997 The comparative hypoxaemic effect of four $\alpha_{2}$-adrenoceptor agonists (xylazine, romifidine, detomidine and medetomidine) in sheep. Journal of Veterinary Pharmacology and Therapeutics 20: 464-471

5. ClarkeK W, Hall L W 1969Xylazine-A new sedative for horses and cattle. Veterinary Record 85: 512-517

6. DeMoor A, Desmet P 1971 Effect of
Rompun ${ }^{\circledR}$ on acid-base equilibrium and arterial $\mathrm{O}_{2}$ pressure in cattle. Veterinary $M$ edical Review 23: 163-169

7. Doherty T J, Pascoe P J, McDonell W N, Monteith G 1986 Cardiopulmonary effects of xylazine and yohimbine on laterally re cumbent sheep. Canadian Journal of Veterinary R esearch 50: 517-521

8. Fayed H A, Abdalla $B$ E, Anderson R R, Spencer K, Johnson D H 1989 Effect of xylazine in heifers under thermoneutral or heat stress conditions. American Journal of Veterinary R esearch 50: 151-153

9. Kokkonen U M, Eriksson L 1987 Cardiovascular and allied actions of xylazine and atropine in the unanaesthetized goat. Journal of Veterinary Pharmacology and Therapeutics 10: 11-16

10. Kumar A, Thurmon J C, Hardenbrook H J 1976 Clinical studies of ketamine hydrochloride and xylazine hydrochloride in domestic goats. Veterinary $M$ edicine and the Small A nimal Clinician 71:1707-1713

11. Kumar A, Thurmon J C 1979 Cardiopulmonary, hemocytologic and biochemical effects of xylazine in goats. Laboratory Animal Science 29: 486-491

12. Magdub A, Johnson H D, Belyea R L 1982 Effects of environmental heat and dietary fibre on thyroid physiology of lactating cows. Journal of D airy Science 65: 2323-2331

13. Mohammed A, Yelwa H A 1993 Effect of xylazine hydrochloride (Rompun ${ }^{\circledR}$ ) on Sokoto red goats. Small Ruminant Research 12: 107-113

14. MogoaE G M 1999Effects of environmental temperature on pharmacokinetics of, and clinical response to xylazine in goats. PhD thesis, University of Pretoria

15. Mogoa E G M, Stegmann G F, Guthrie A J, Swan G E 2000 Clinical, cardiopulmonary and haemocytological effects of xylazine in goats after acuteexposure to different environmental temperature and humidity conditions. Journal of theSouth A frican Veterinary Association 71: 153-159

16. Nolan A, Livingston A, Waterman A 1986 The effects of $\alpha_{2}$ adrenoceptor agonists on airway pressure in anaesthetized sheep. Journal of Veterinary Pharmacology and Therapeutics 9: 157-163

17. O'Hair K C, McNeil J S, Phillips J J 1986 Effects of xylazinein adult sheep. Laboratory Animal Science 36: 563

18. Raekallio M, Hackzell M, Eriksson L 1994 Influence of medetomidine on acid-base balance and urine excretion in goats. A cta Veterinaria Scandinavica 35: 283-288

19. Raekallio M, Tulamo R M, Valtamo T 1998 Medetomidine-midazolam sedation in sheep. A cta Veterinaria Scandinavica 39: 127-134

20. Raptopoulos D, Weaver B M Q 1984 Observations following intravenous xylazine administration in steers. Veterinary Record 114: 567-569

21. Saleh A S 1993 Antagonistic effect of doxapram after Rompun ${ }^{\circledR}$ treatment with special reference to acid-base balance in goats. Assiut Veterinary M edical Journal 29 (57): 208-214 